\title{
Article \\ The Benefit of Rail: Estimating the Impact of Station Accessibility on Residential Property Prices
}

\author{
Dániel Tordai (i) and András Munkácsy *D \\ KTI Institute for Transport Sciences Non Profit Ltd., 1119 Budapest, Hungary; tordai.daniel@kti.hu \\ * Correspondence: munkacsy.andras@kti.hu; Tel.: +36-13715912
}

\begin{abstract}
This article focuses on the relationship between the prices and the distance from a metro or commuter railway station to residential properties. Relevant efforts have already been dedicated to estimating the effect of station accessibility, but one of the key limitations of previous studies was the heterogeneity of real estate. Here, the data on homogeneous real estate type in Budapest, Hungary, namely panel flats (built with uniform technology between the 1960s and 1990s) are analysed by statistical methods. First, it is demonstrated that this real estate type is indeed highly homogenous. Second, linear regression is used to understand the relationship and its magnitude between flat prices and distance of stations. The results show a statistically significant relationship, i.e., that five additional minutes of travel time to the nearest station providing fast access to the city centre makes real estate prices drop by nearly $1 \%$. In light of current policies promoting rail for passenger transportation, the findings may be applied for value capture policies to increase the viability and feasibility of urban railway projects.
\end{abstract}

Keywords: residential property; public transportation; metro; rail; flat

Citation: Tordai, D.; Munkácsy, A. The Benefit of Rail: Estimating the Impact of Station Accessibility on Residential Property Prices. Buildings 2022, 12, 222. https://doi.org/ 10.3390 /buildings 12020222

Academic Editors: Liyin Shen, Jorge Ochoa and Haijun Bao

Received: 30 December 2021 Accepted: 14 February 2022 Published: 16 February 2022

Publisher's Note: MDPI stays neutral with regard to jurisdictional claims in published maps and institutional affiliations.

Copyright: (C) 2022 by the authors. Licensee MDPI, Basel, Switzerland. This article is an open access article distributed under the terms and conditions of the Creative Commons Attribution (CC BY) license (https:// creativecommons.org/licenses/by/ $4.0 /)$.

\section{Introduction}

In light of the speed of urbanization around the world, making cities more sustainable has become a key global challenge [1]. Enhancing urban transportation and mobility by environmentally sound technologies and measures is found to be one of the best practices, particularly in Europe [2]. The New Urban Agenda of the United Nations envisages cities that promote sustainable, safe and accessible urban mobility by means of resource-efficient transport systems worldwide [3]. The mobility strategy of the European Commission [4] aims to improve current policy and financial frameworks regarding mobility management, urban planning and connectivity in order to achieve sustainable and healthy mobility in urban areas. It sets the ambitious targets of 100 climate-neutral cities and fully carbonneutral scheduled collective travel for short journeys (under $500 \mathrm{~km}$ ) in Europe by 2030. It is expected that shifting more activity towards more sustainable transport modes, especially commuting by public transport and travelling by rail, may significantly contribute to reaching these goals.

The backbone of most urban transportation systems is railway networks. Metro and suburban rail provide fast and high-capacity service towards the central business district (CBD) at a relatively low operational cost. However, cities usually face difficulties in building and developing such networks, primarily due to technical system complexity and related high upfront investment costs. The costs of these projects may be partly funded or recovered through value capture policies, such as cities extracting and internalizing some of the externalities of new railway infrastructure that appears in the value of properties close to newly built stations. To implement such policies, it is crucial to understand how the accessibility to CBD provided by public transport affects residential property prices. Nevertheless, heterogeneity in attributes and quality of real estate makes this pretty complicated. 
This paper intends to extend the knowledge about the relationship of accessibility by public transport and real estate price. It focuses on a homogeneous type of real estate in Budapest (Hungary), namely flats in panel buildings (hereinafter: panel flats). Panel flats were built in the second half of the 20th century to address the housing crisis by applying an almost uniform technology [5] of a large-panel system and featuring similar characteristics in terms of comfort level, design principles and living quality. It is expected that through the analysis of this unique subset of real estate, a more robust conclusion can be reached.

First, the homogeneity of panel flats will be presented to reveal that their quality is unrelated to their location, especially their closeness to rail services (Hypothesis_1). On this basis, travel time to CBD by public transportation and to the nearest metro or commuter railway station will be examined. As another hypothesis of this research, it is supposed that flats with better connectivity are priced higher, i.e., travel time between a property and the nearest railway station is negatively correlated with its purchase price (Hypothesis_2).

The extensive literature about the relationship of public transportation accessibility and real estate value is generally based on the bid-rent theory first introduced by William Alonso [6] to describe how increased distances from the CBD affect the demand for and price of real estate, i.e., indicating that instead of paying high prices for land (real estate) in city centres, commuters spend their money and time when they travel daily from their place of residence to the CBD. In this theoretical framework, a new public transportation connection to the city centre should increase the price of nearby real estate, as it provides a faster and cheaper route to the CBD, as if the property moved closer to the city centre.

From the 1990s, scholars applied this theory to analyse real life data and most have found the expected positive relationship, with very different magnitudes (Table 1), between high-capacity public transportation and residential real estate prices in a variety of cities worldwide, e.g., Laakso [7] for Helsinki, Grass [8] for Washington DC, Dubé et al. [9] for Montreal, Ibeas et al. [10] for Santander, and Cordera et al. [11] for Rome and Santander. Others have found no significant impact, or even a negative impact, of better public transportation accessibility on property prices, e.g., Debrezion et al. [12] in the Netherlands and Anderson et al. [13] in Taiwan.

Table 1. Findings in the literature on the effects of railway on residential property prices.

\begin{tabular}{cccc}
\hline Source & Location & Type of Rail & \% Change \\
\hline Laakso [7] & Helsinki, Finland & metro & 3.5 to 6\% \\
\hline Grass [8] & Washington, DC, USA & metro & $19 \%$ \\
\hline Dubé et al. [9] & $\begin{array}{c}\text { Montreal South Shore, } \\
\text { Canada }\end{array}$ & commuter rail & $2.6 \%$ on average \\
\hline Ibeas et al. [10] & Santander, Spain & suburban train & $-4.9 \%$ \\
\hline Andersson et al. [13] & Southern Taiwan & high-speed railway & $\sim 0$ \\
\hline Debrezion et al. [12] & 3 cities in The Netherlands & railway & 0 to $2 \%$ \\
\hline
\end{tabular}

In their review of the previous literature, Debrezion et al. [14] summarized the findings of 57 papers about the impact of railway stations on real estate prices. They found that both heavy (by $0.9 \%$ ) and commuter rail (by 14\%) stations have larger overall effects on residential property prices than light railway stations. They also found that the inclusion of other accessibility factors significantly reduces the impact of metro stations. A metaanalysis on the basis of 102 observations from the review of 23 papers by Mohammad et al. [15] led to similar outcomes about commuter rail providing fast access to the CBD, but their results suggest that heavy rail has equal or even lower impact than light rail, probably due to effects of the former on the environment, i.e., that it adds less economic value to the environment around stations. A literature review by Higgins and Kanaroglou [16] in North America also found that properties closer to railway stations are generally more valuable, and stated that the sources of diversity in the related research outcomes are 
omitted variables, unobserved land value uplift impacts and misvalued results. A property in the near proximity of a station can also lose value due to the negative externalities, such as noise and increased traffic, especially in the case of heavy rail. As there has seemingly been little or no previous effort or no opportunity to include a homogeneous set of real estate in this type of analysis, the above-mentioned approach, namely the study of a specific subset in a specific location (i.e., panel flats in Budapest) promises new results in this line of research.

The paper is structured as follows: Section 2 details the data and methods used in this paper, and Section 3 provides the results, followed by a discussion in Section 4.

\section{Materials and Methods}

The analysis consisted of two steps to show the effect of high-capacity railway connection on residential property prices, both based on commonly used statistical models. First, the characteristics of panel flats were plotted for visualization and regression analysis was applied to show that the quality of panel flats is unrelated to the proximity of railway stations. As part of this analysis, travel times to the nearest railway station and to the CBD were calculated. In the second step, another linear model was used to estimate the impact of the travel time to the $\mathrm{CBD}$ on real estate prices.

Budapest (1.7 million inhabitants in early 2021) is the capital city of Hungary. In this case study, the key elements of its extensive public transportation network were considered: metro (4 lines, approx. $40 \mathrm{~km}, 52$ stations) and commuter rail (4 lines +1 side line, $97 \mathrm{~km}$, 69 stations). A total of 31 stations are outside city boundaries and there are 2 stations with direct metro-commuter rail connection, i.e., the number of stations included in this analysis was 88 .

The metro and commuter railway lines were built during very different time periods: metro (underground) line M1 opened in 1896, M2 in 1970 (a later stage was added in 1972), M3 in 1976 (later stages were added until 1990) and M4 in 2013. Commuter railway lines were built between 1887 and 1952. In the early 2020s, modern trains (built in 2008 to 2014 or modernized in 2016 to 2018) circulate on all metro lines. Commuter rail services are operated by trains built between 1963 and 1983, which underwent only minor refurbishment over the years.

These lines are the backbones of the urban public transportation system, providing fast and reliable connection between several areas of the outskirts or some of the major transportation hubs and the CBD. Headway during peak hours is 2 to $3 \mathrm{~min}$ in the metro and 6 to $8 \mathrm{~min}$ in the commuter rail network. The tariff system encourages the use of monthly (or quarterly or yearly) passes, which provides passengers with unlimited journeys for an economic price: e.g., a monthly Budapest Pass costs 9500 HUF (approx. 27 EUR (approx. 27 EUR, by applying the average conversion rate of 355 HUF/EUR by the National Bank of Hungary in April 2020)for adults and 3450 HUF (10 EUR) for students, while single tickets cost HUF 350 HUF (1 EUR) for all.

In this research, two datasets are used:

- dataset_1: data containing characteristics of individual panel flats. This is a selfcollected dataset scraped from online property advertisements on a real estate advertisement site;

- dataset_2: data on the size and purchase price of panel flats. This contains average values from aggregated data for each census tract in Budapest, acquired from the official database of the Hungarian Central Statistical Office (hereinafter: KSH).

The workflow is presented in Figure 1. 


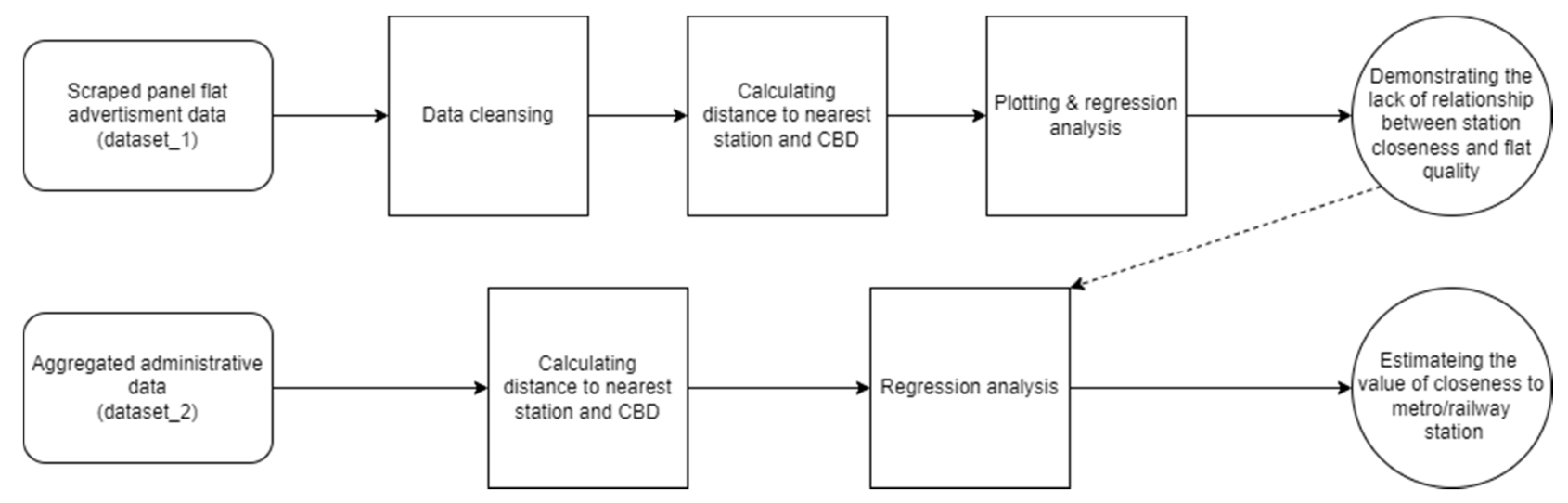

Figure 1. Workflow of the paper.

\subsection{Panel Flats in Budapest}

In Budapest, approx. 190,000 panel flats were built from the 1960s to the 1990s, generally in large housing estates using mostly prefabricated elements, usually pre-cast concrete panels. Four housing factories were built in Budapest from 1965 to 1974, which used a modified version of the Soviet large-panel system and, briefly, the Larsen-Nielsen system developed in Denmark. On the basis of centralized plans, panel flats were intended to solve the housing issues of the quickly growing population of the Hungarian capital city by providing cheap and, at the time, modern accommodation to families [17].

In order to determine whether the proximity to a station is related to the quality of panel flats, all advertisements of panel flats in Budapest in April 2020 (in sum, 3754) were searched from ingatlan.com (accessed on 15 January 2022), the leading [18] property advertisement site in Hungary, resulting in dataset_1. To collect all characteristics of these advertised flats, a self-written code was used (the code is available here: https: / / bit.ly/2Y6BKSg (accessed on 15 January 2022)), which looked for every real estate advertisement within the city boundaries of Budapest, listed as a panel flat by the advertiser, and then downloaded all available information. The dataset was cleansed by dropping outliers (the top and bottom $1 \%$ in terms of price and size) and unrealistic values, leading to a sample of 3607 items. Despite the fact that this was a non-representative sample of the full subset of panel flats in the city and that the amount of information about real estate characteristics in the advertisements was rather diverse, both the sample size and the availability of basic characteristics for all items indicated that the sample was appropriate for the purpose of this study.

As expected, the panel flats in the sample were very similar in many respects:

- As all of the sample items featured modern conveniences such as heating, flush toilets, bathrooms and kitchens, it could be deduced that all panel flats in Budapest do too;

- In approx. $85 \%$ of sample flats, heating is provided through district heating (a way of heating where hot steam is generated in a distant plant and then the steam is transported to the residential buildings in pipes);

- The bathroom and toilet were in separate rooms in $78 \%$ of flats;

- The clear height was less than $3 \mathrm{~m}$ in almost all apartments (98.98\%);

- Almost none of them (1.65\%) had direct access to a garden;

- Other characteristics differentiated the panel flats:

- Floorspace, which diverged between 30 and $80 \mathrm{~m}^{2}$ with an average of about $54 \mathrm{~m}^{2}$ (Figure 2).

- The vast majority of such flats had either two $(44.05 \%)$ or three rooms $(44.14 \%)$. (Half rooms were included in this study as full rooms, as definitions are varied and advertisements may not be consistent in this regard.)

- Year of construction, as approximately half of the sample items were built in the 1960s and 1970s (47.09\%), and half were built in the 1980s or, eventually, the 1990s (52.16\%). 
(Most blocks were built before the end of Socialism in 1990 and only ongoing projects were finished in the early 1990s.)

- Seemingly, about half (50.84\%) of the flats had a balcony, most of which were found to be rather small $\left(95 \%\right.$ were under $6.76 \mathrm{~m}^{2}$, mean: $\left.4 \mathrm{~m}^{2}\right)$. However, data on balconies were not included in further analyses, as providing information is optional on the advertisement site and, therefore, advertisers may have (un)intentionally omitted it from the advertisements.

- Overall, $75.45 \%$ of the flats were located in 10 -story or higher buildings and $15.25 \%$ were located in 4-story buildings, which were representative of the panel blocks in the city. The rationale behind building 4 or 10 levels was that regulations required the construction of an elevator above 4 levels. So these two sizes were the most economical to build: 4-level houses without an elevator and 10-level ones, where the higher number of flats compensated for the extra cost of the elevator.

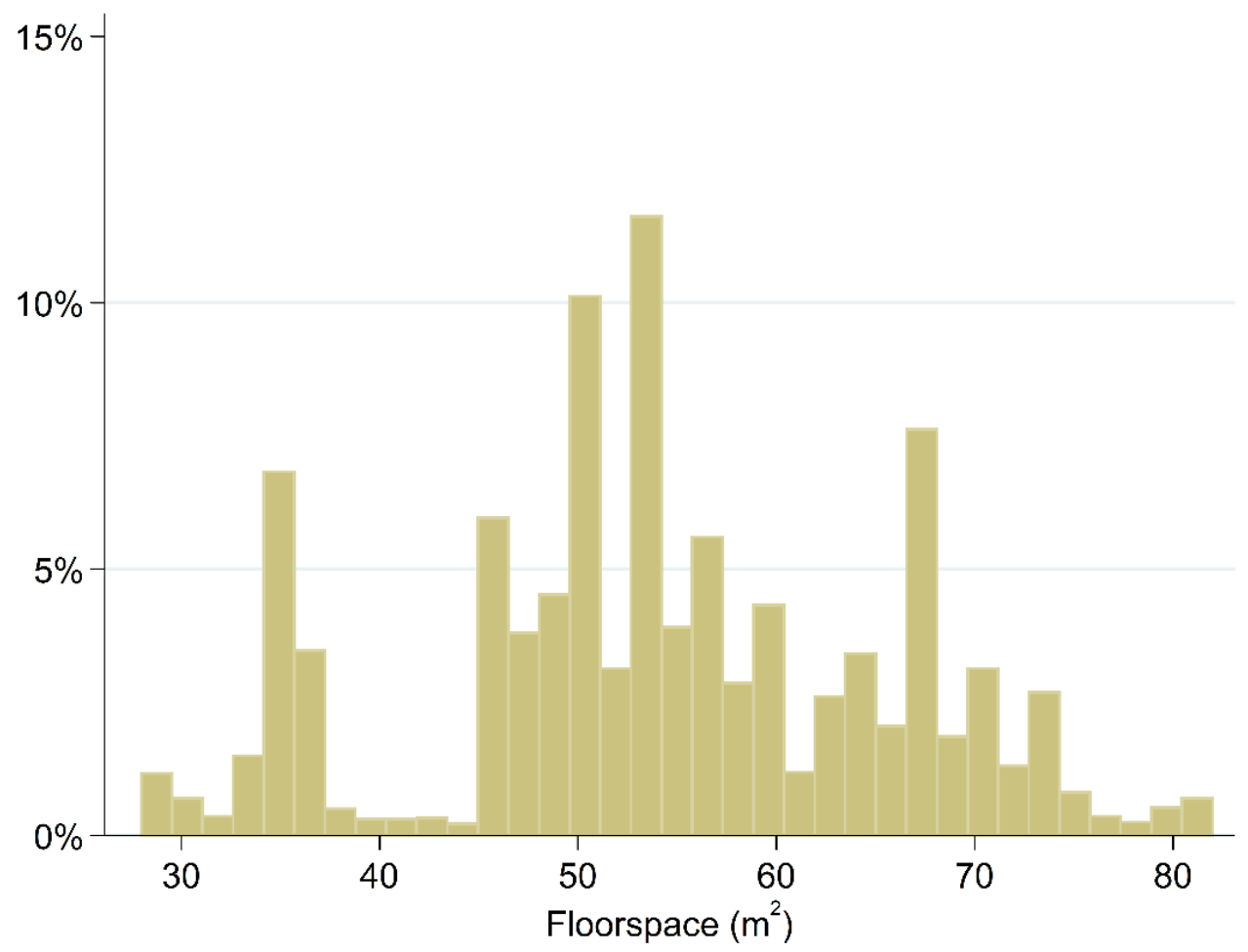

Figure 2. Distribution of floorspace.

The flat price varied between 12 and 62 million HUF (approx. 33,802 and 174,647 EUR, respectively), with an average of 30.6 million HUF (86,197 EUR). The per-square-meter price of flats varied between 386,000 and 955,000 HUF (1087 and 2690 EUR, respectively), with an average of 575,000 HUF (1619 EUR). Histograms of both variables are presented in Figure 3. In light of the fact that panel housing estates were built in areas with different characteristics (e.g., in the very popular hilly areas of Buda or the less attractive outskirts of Pest), this wide range of prices for an otherwise homogeneous property type indicates that panel flats in Budapest are inhabited by a diverse population.

\subsection{Travel Time Calculation}

Travel times between the flats to the nearest station and between the flats and the CBD were calculated using the publicly available API of HERE Maps. This combines all travel options by public transport in Budapest (except for suburban, regional and long-distance bus services, but this is negligible, as these services are rather irrelevant in terms of urban journeys within city boundaries). 

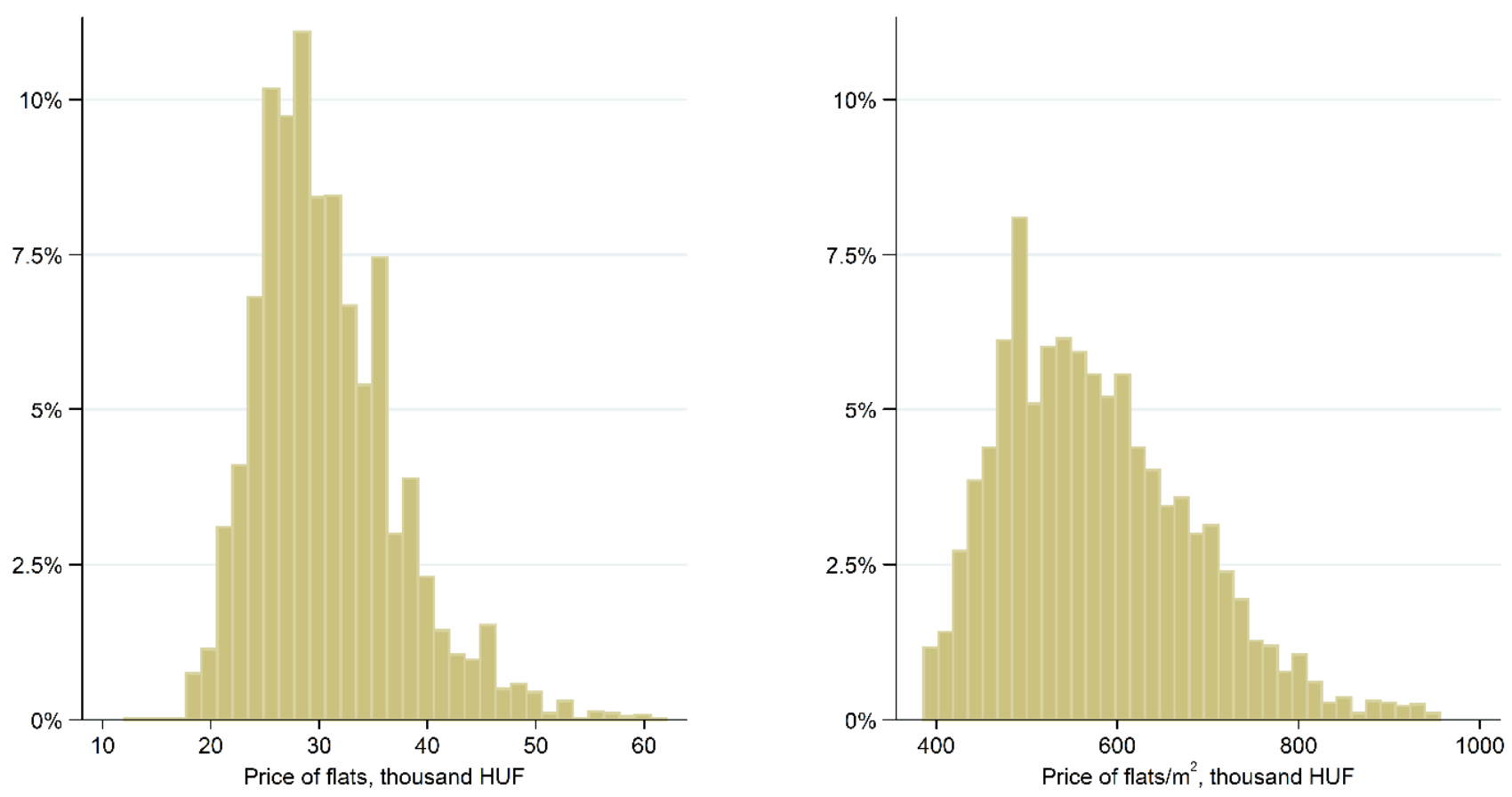

Figure 3. Distribution of flat prices.

To calculate the shortest travel time within which railway services could be accessed from a flat, the algorithm calculated the fastest route by public transport (or by foot, if faster) between an individual flat and all the railway stations and chose the shortest one.

To reveal travel times to the CBD, the API calculated the travel time between a flat and a reference point in the city centre, namely Astoria metro station (hereinafter in the analysis: CBD). Astoria is a major road intersection and a metro station of line M2 (named after a luxury hotel), between two large central interchanges: Deák Ferenc tér, where M1, M2 and M3 stop, and Kálvin tér, where M3 and M4 stop. By this choice, passengers are not excessively penalized for the use of any of the commuter railway or metro lines, since Astoria is within walking distance to all metro lines. Line M2 has 2 stations where passengers can directly transfer from metro to commuter rail lines (H5, H8 and H9). Additionally, there are 8 bus and 2 tram lines crossing the road intersection at Astoria.

All journeys to the CBD were planned to start at 8 a.m. on the same working day (a Monday) morning.

Travel times to the CBD were mostly found to be between 20 and $60 \mathrm{~min}$ (min: $14 \mathrm{~min}$; max: 70 min; Figure 4), clearly indicating that only a small proportion of panel flats are located in the city centre (and if this is the case, panel flats are located in outer areas of inner districts, about 20-30 min from the CBD).

Travel times to the nearest metro or commuter railway station varied depending on the location (mean: 17.44 min; min: 1.17 min; max: 48 min; Figure 5).

\subsection{Real Estate Prices}

For the sake of data protection, only aggregate data on real estate purchases, i.e., not the record of individual flats but the aggregate data of a minimum of 3 purchases may be requested from the $\mathrm{KSH}$. In light of this, three criteria were considered for this data request for dataset_2: (1) census tracts (including 100-150 addresses) are homogeneous neighbourhoods featuring near-identical panel houses of uniform distribution of flats; (2) two consecutive years of data ensure a relatively long timeframe so that the above mentioned threshold is reached; and (3) two different periods would let us reveal if rising real estate prices [19] lead to relevant changes in the context of this study. Consequently, the requested dataset contained two aggregate datasets of two consecutive years (2014-2015 and 2018-2019) for all the census tracts including panel flats in Budapest. The average 
number of transfers in a census tract that was aggregated in dataset_2 was 9.1 (minimum: 3; maximum: 35; standard deviation: 4.2). As both the average flat size and average contract price were provided, the average price per square meter in a tract could be calculated.

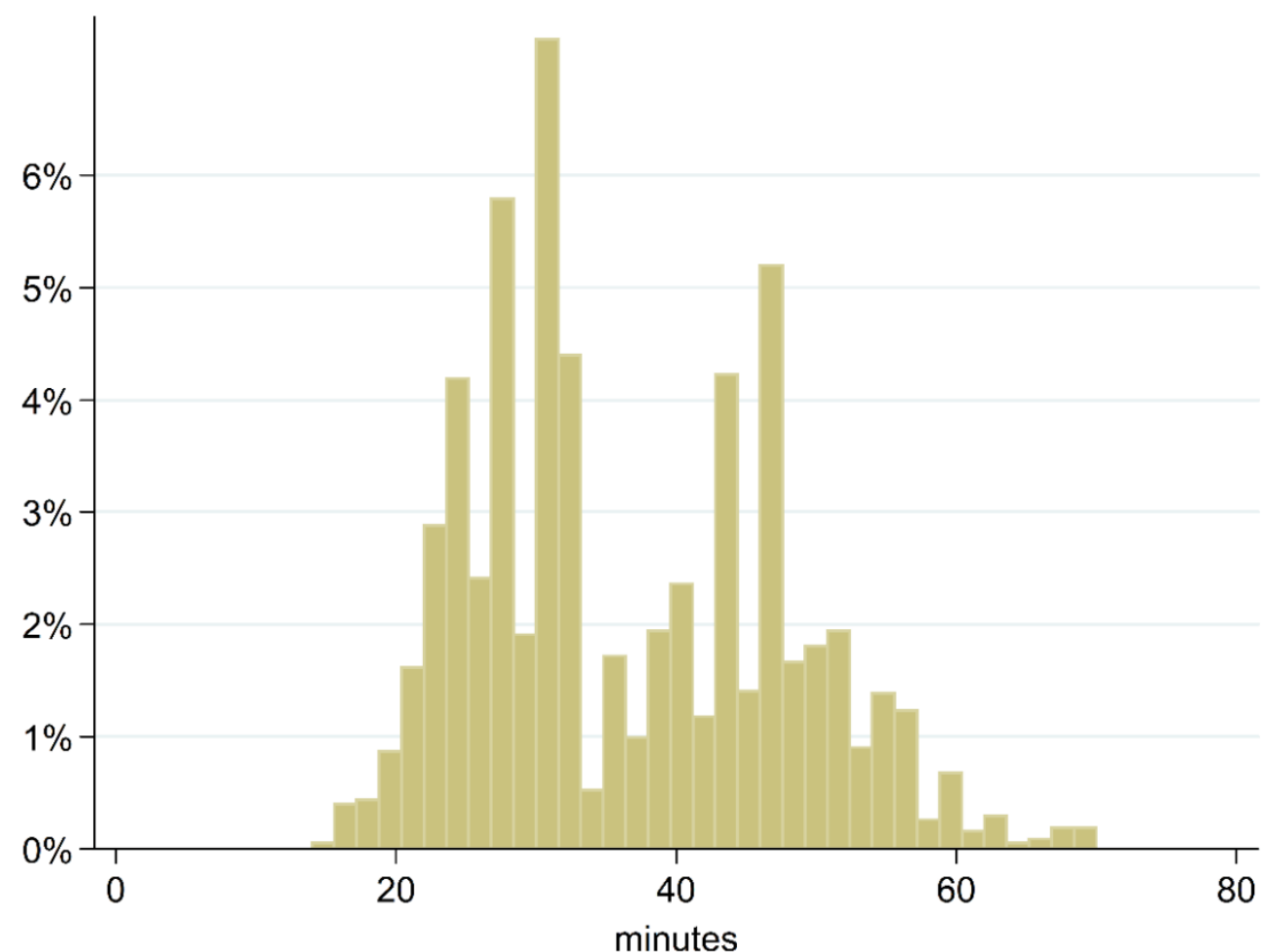

Figure 4. Distribution of the travel times to CBD.

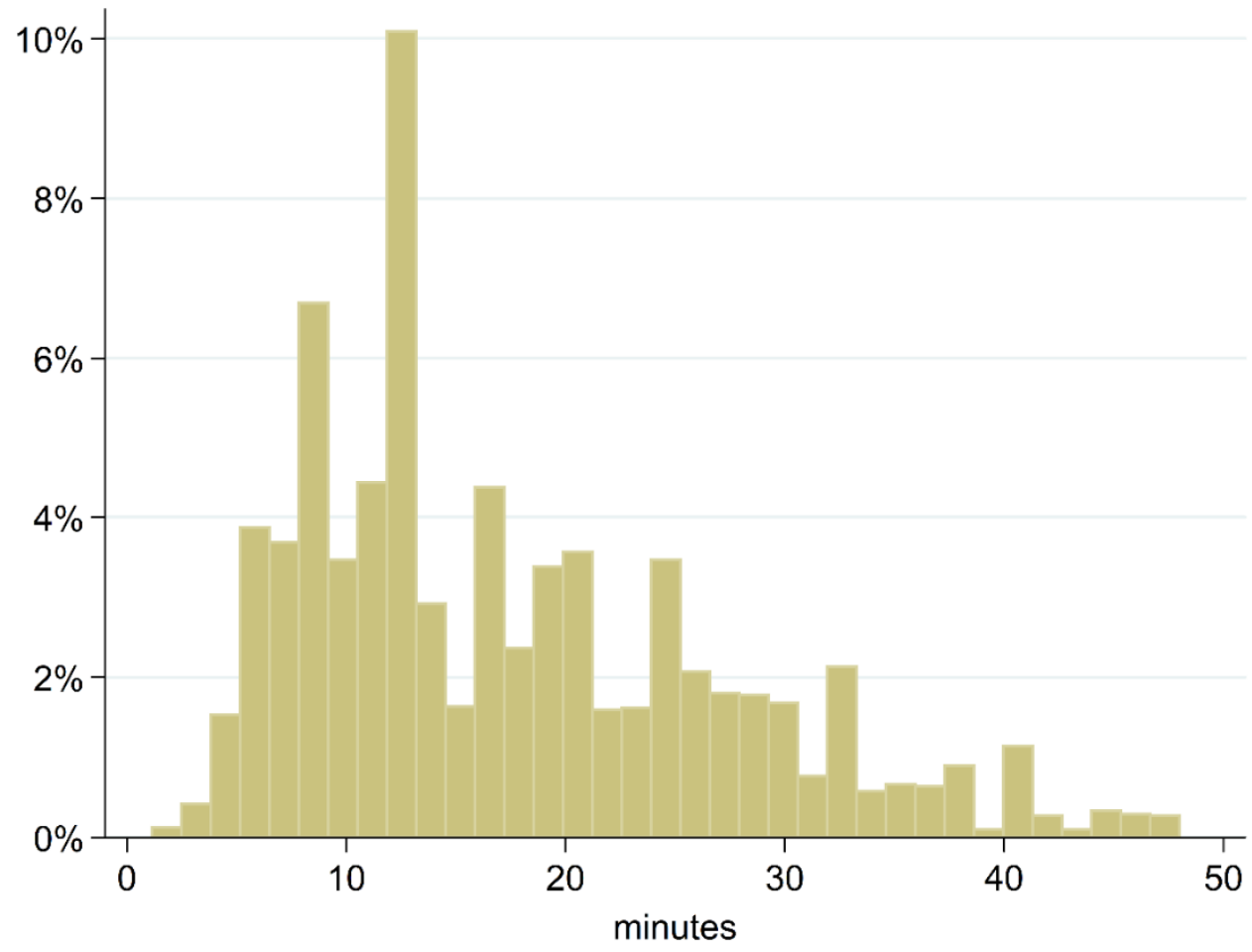

Figure 5. Distribution of travel times to the closest metro and commuter railway station. 
The two explanatory variables used in dataset_2 were travel time to the nearest station and travel time to the CBD, both measured in minutes. For the calculation of these variables, the same HERE Maps API was used (as in the case of dataset_1, detailed in Section 3.1). The starting point of journeys was the geographical centre of a census tract and the travel mode was set to public transportation in both cases. Distributions can be seen in Figures 6 and 7 , as well as in Appendix A.

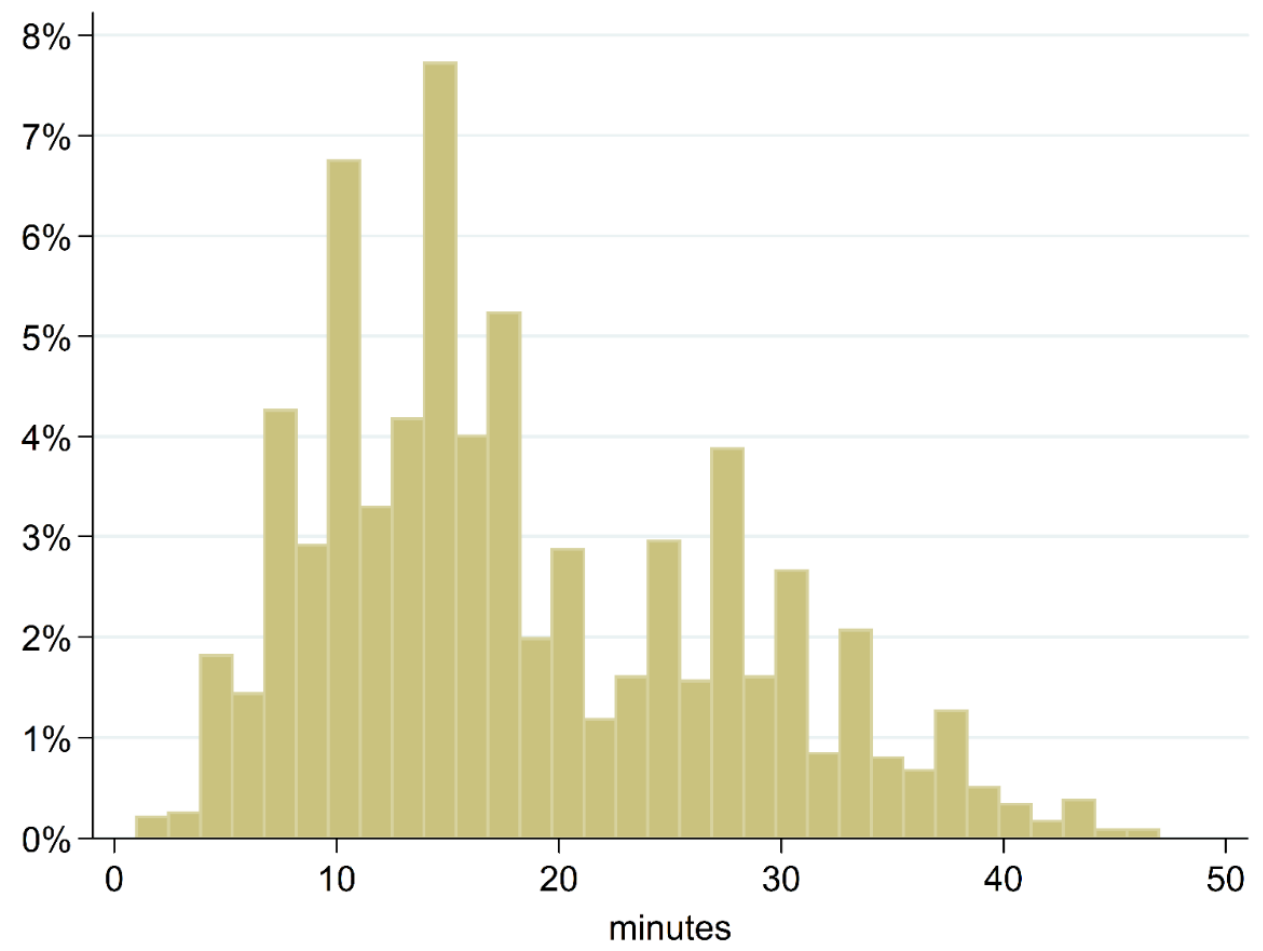

Figure 6. Distribution of travel time to the station.

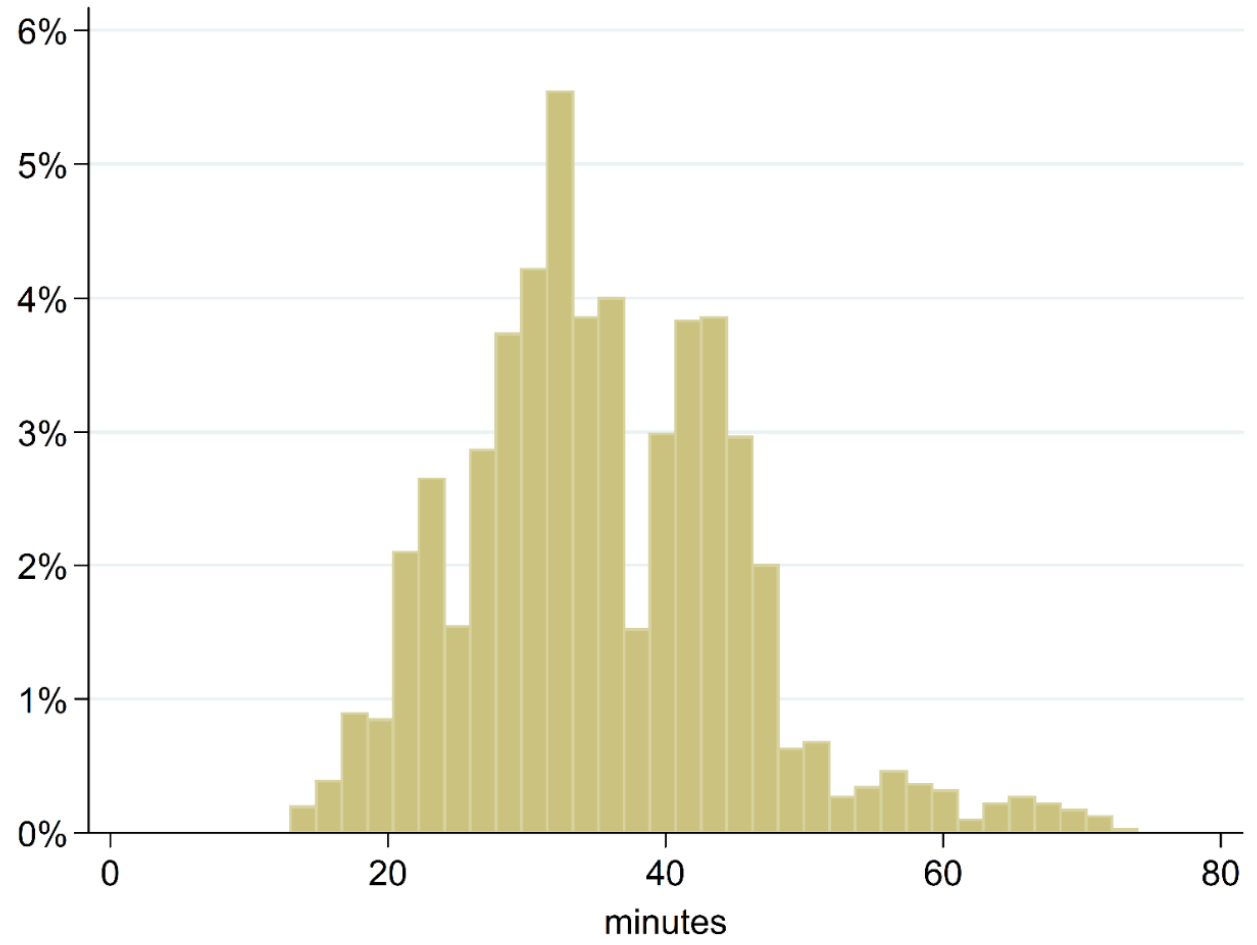

Figure 7. Distribution of travel times to the CBD. 


\section{Results}

\subsection{Travel Time to Stations and Quality of Flats}

As the first step to test Hypothesis_1, i.e., if the location and the quality of a panel flat are unrelated, floorspace was plotted against travel time from the nearest station (Figure 8). A kernel-weighted local polynomial regression was also visualized (fitted values are displayed with a red line and the $95 \%$ confidence interval is marked by a grey area). As the slope of the line is very close to zero, it can be seen that there was basically no relationship between floorspace and the travel time from the nearest station. In other words, it could be assumed that the effect of the quality of the flats would not be taken up by the travel time variable in later steps of this study. The same attribute was plotted against the travel time to the CBD (Figure 9), showing a similar outcome, namely, that there was no or no significant relationship. The rest of the attributes showed even less variance, as detailed in Section 2.1.

In order to explore the relationship between variables in a more robust way, the travel time to the nearest station and to the CBD on square meter prices were regressed in six variations, using different combinations of variables. In the first one, only the two distance variables were included, imitating the regression that was run on dataset_2, due to the difference in available information in dataset_1 and dataset_2. In the other models, further attributes of flats (or the building) were controlled for, with diverse specifications to show the robustness of the model, i.e., the number of rooms, floorspace, if the toilet is located in the bathroom, availability of an elevator in the building, year of construction (before or after 1980) the floor on which the flat is and the state of the flat as indicated by the advertiser (excellent, to be renovated, etc.). Based on the results (Table 2), out of models 2 to 6 , model 6 (including all the above variables) seemed to be the most appropriate one in terms of the information criteria. Plotting the residuals against the variables indicated that the relationship between the independent and dependent variables was indeed linear.

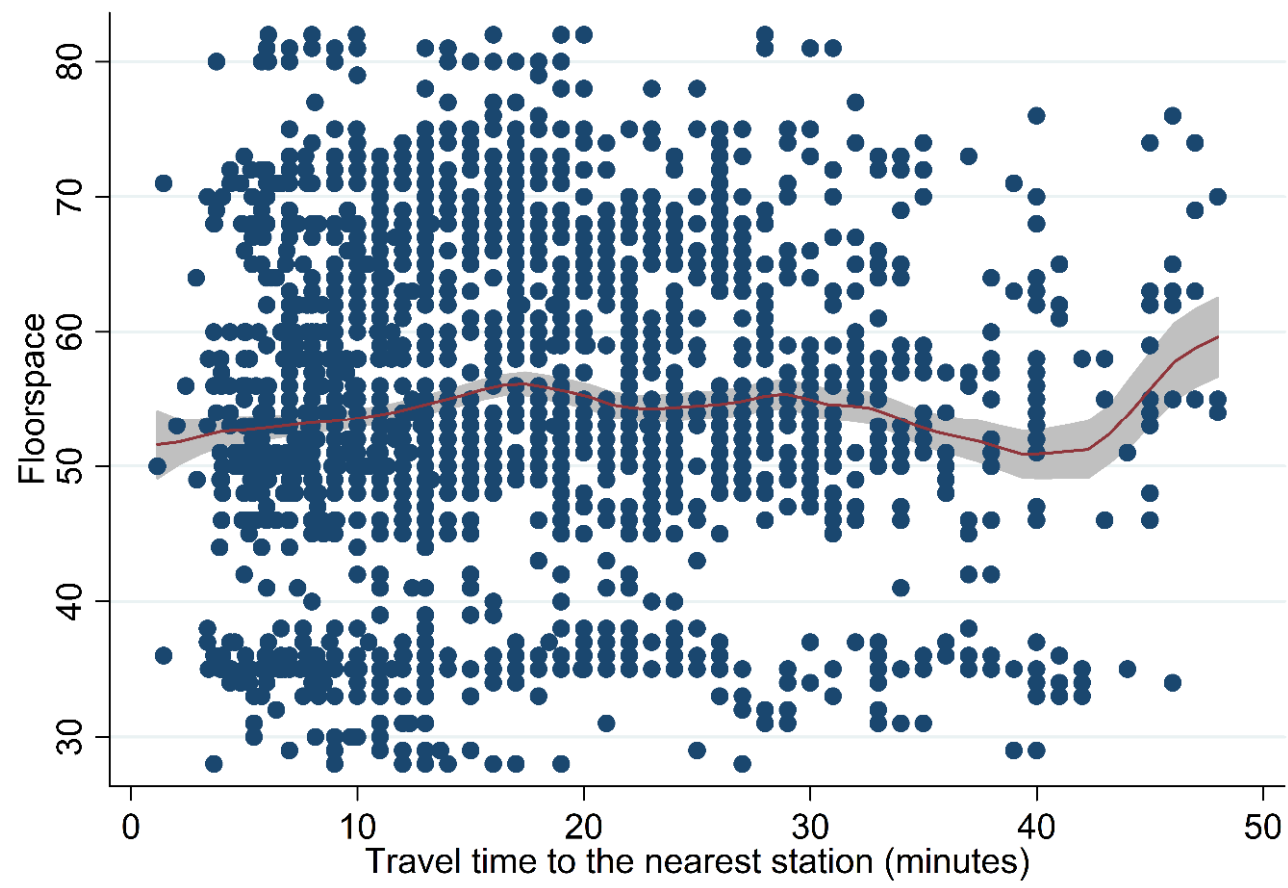

Figure 8. Floorspace plotted against travel time to the station. 


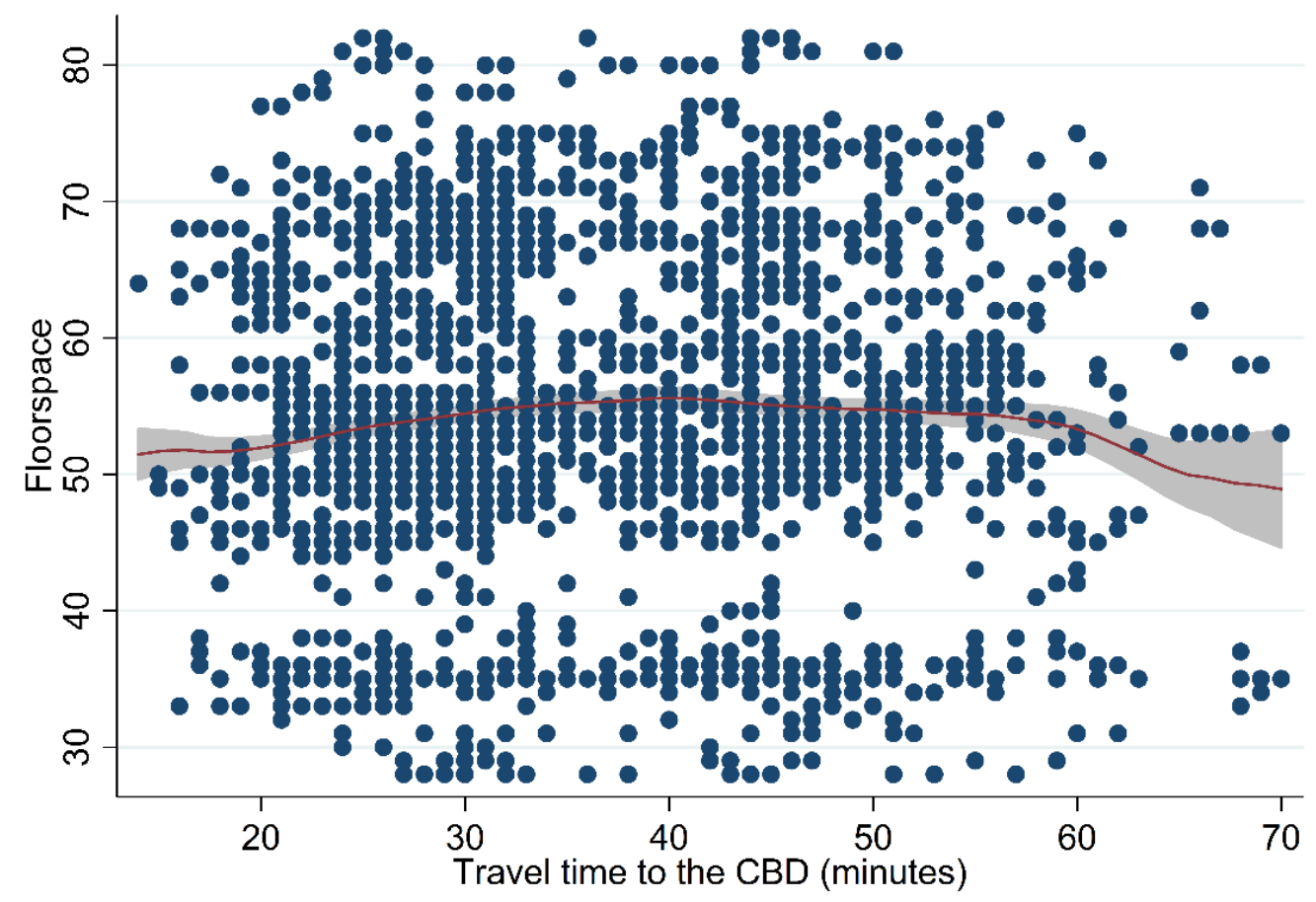

Figure 9. Floorspace plotted against travel time to the CBD.

Table 2. Regression results for panel flat attributes' impacts on price.

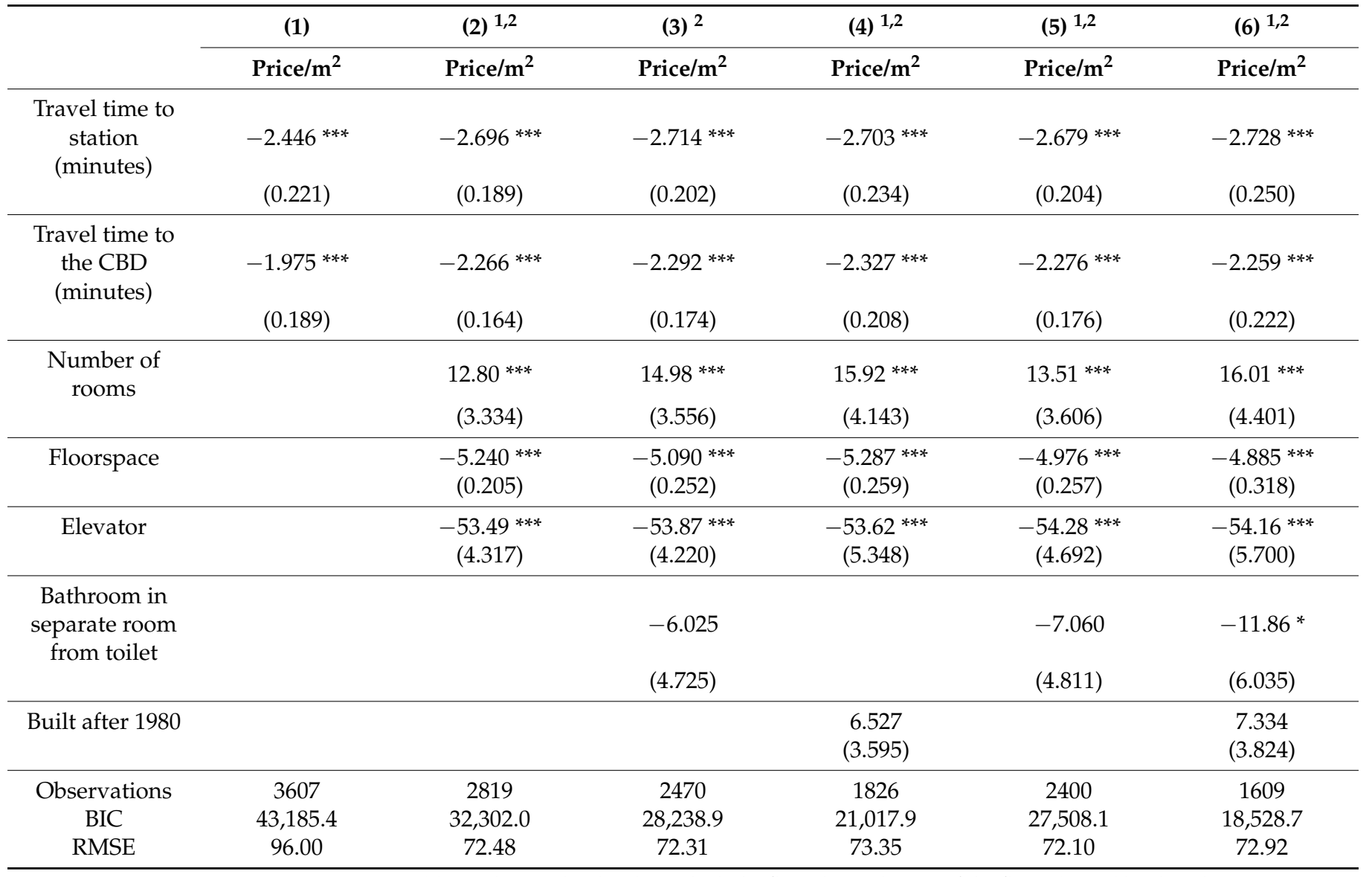

Note: Additional controls-level on which the flat is located, state of the flat indicated by the advertiser. ${ }^{*} p<0.1$; ${ }^{* * *} p<0.01{ }^{1}$ Controlled for the floor on which the flat is; ${ }^{2}$ Controlled for the stated quality of the flat. 
The Wald test was used to formally check whether the coefficients of the variable showing travel times to the closest station or CBD were the same. The results (Table 3) indicate that the null hypothesis could not be rejected in either of the two models.

Table 3. Wald test results.

\begin{tabular}{cc}
\hline Model 1 (Travel time to station) $=$ Model 6 (Travel time to station) \\
\hline $\mathrm{chi}^{2}(1)$ & 1.54 \\
Prob $>\mathrm{chi}^{2}$ & 0.21 \\
\hline Model 1 (CBD distance) $=$ Model 6 (CBD distance) \\
\hline $\mathrm{chi}^{2}(1)$ & 1.97 \\
\hline Prob $>\mathrm{chi}^{2}$ & 0.1606 \\
\hline
\end{tabular}

However, just because the hypothesis could not be rejected, the coefficients of the variables were not necessarily the same. Regardless of the exact specification of the model, the coefficients of the two explanatory variables were larger (in absolute terms) in Model 2-6 than in Model 1. If Model 1 was used to estimate the impact of the proximities of a station and the CBD on the quality of a flat, the size of this impact would be underestimated. Thus, the results of this estimation could be used on a larger dataset, too, as overestimation of the effects of these variables is unlikely.

In summary, it may be stated that the quality of panel flats was unrelated to travel time to the nearest station or the CBD. In many attributes, flats in this dataset featured identical characteristics (kitchen, bathroom, inner height) and other varying attributes (e.g., floorspace, number of rooms) were weakly or non-related to the distance of either the nearest station or the CBD. Finally, even if the attributes of the properties were related to the distance, leaving them out from the regression could have led to underestimation of the coefficients, so there was no chance of overestimation when evaluating the effects.

\subsection{Travel Time to Station, Accessibility and Panel Flat Prices}

As it was proven that the quality of panel flats in Budapest is not related to the travel time to the nearest station (and the CBD), the effect of this distance on the real estate price could be estimated. For that, dataset_2-i.e., a dataset with less information on the quality of flats but containing information on actual sales of all panel flats in Budapest-was used. First, average real estate prices in census tracts in 2014-2015 were plotted against travel times to the nearest station in Figure 10 and to the CBD in Figure 11.

The fitted non-parametric trend indicates that their relationships were close to linear; thus, a linear model could be used for this estimation (Equation (1)).

$$
\text { mean price }=\beta_{0}+\beta_{1} * \text { travel time to the nearest station }+\beta_{2} * \text { travel time to } C B D
$$

Models calculated using the log of the mean prices of 2014-2015 and 2018-2019 as dependent variables can be seen in Table 4 . Post regression analysis here also confirmed the linear relationship between the variables.

The results were statistically significant and show that residential real estate nearer to a station and to the CBD is more valuable: e.g., each five additional minutes of travel time to the nearest station caused the per-square-meter prices to drop by nearly $1 \%$. This applied to both examined periods, i.e., independently of the changing price levels from 2014-2015 to 2018-2019. 


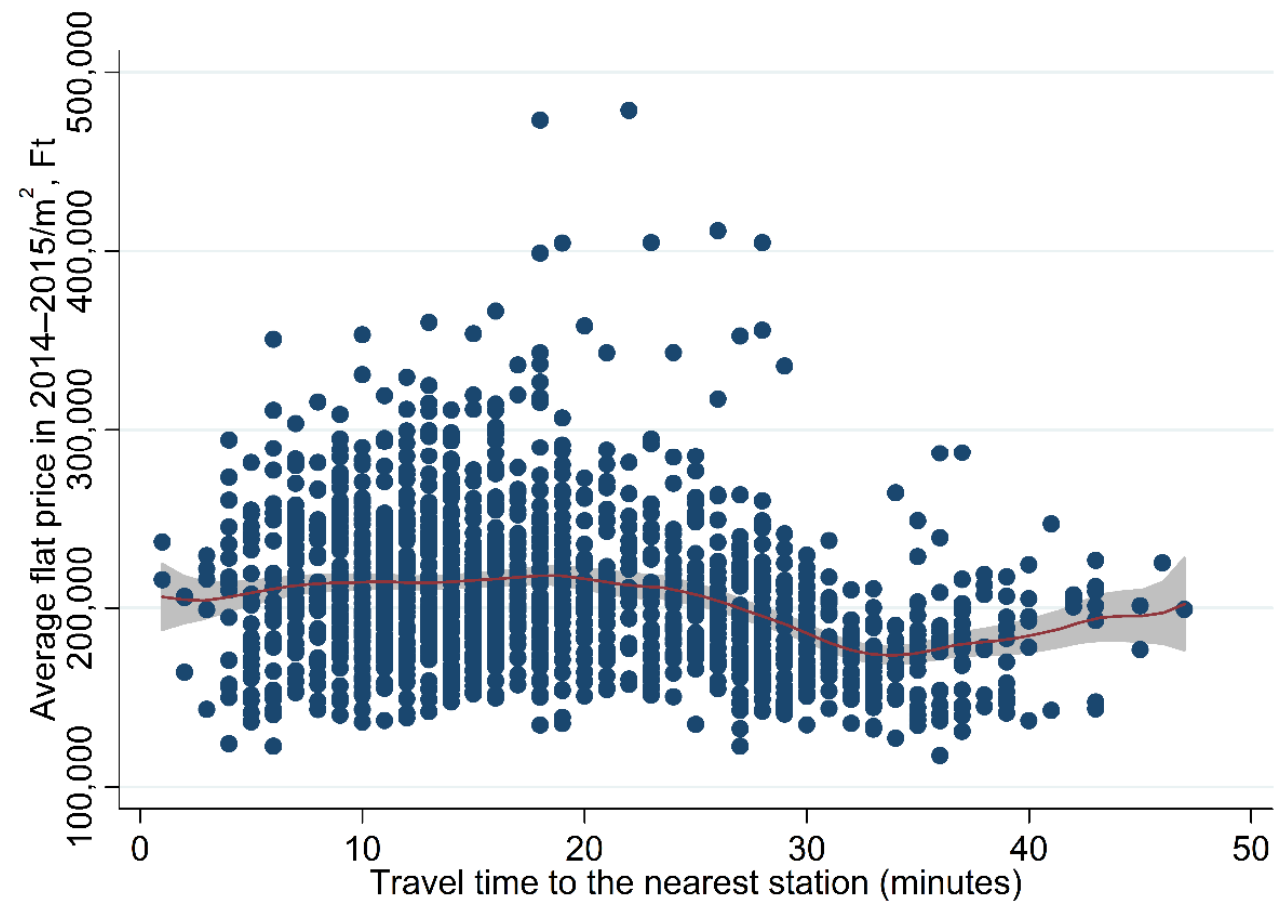

Figure 10. Average panel flat price plotted against travel time to the station.

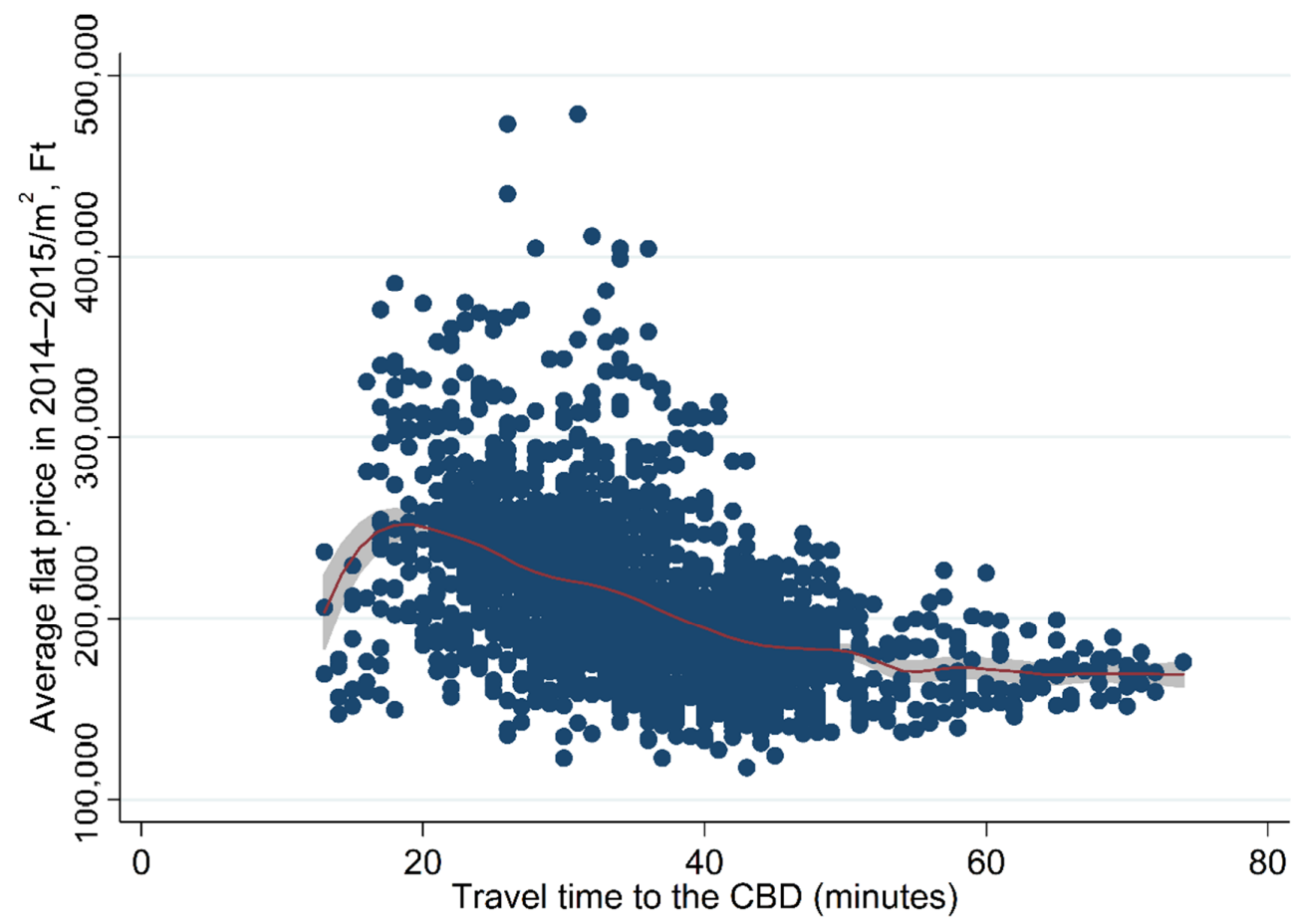

Figure 11. Average panel flat price plotted against travel time to the CBD. 
Table 4. Regression results of travel time to the nearest station and CBD on flat price.

\begin{tabular}{|c|c|c|}
\hline & $\begin{array}{c}\log \left(\text { Mean Price } / \mathrm{m}^{2}\right) \\
\text { 2014-2015 } \\
\text { (1) }\end{array}$ & $\begin{array}{c}\log \left(\text { Mean Price } / \mathrm{m}^{2}\right), \\
\text { 2018-2019 } \\
(2)\end{array}$ \\
\hline \multirow{2}{*}{$\begin{array}{l}\text { Travel time to the CBD } \\
\text { (minutes) }\end{array}$} & $-0.009 * * *$ & $-0.008^{* * *}$ \\
\hline & $(0.0005)$ & $(0.0004)$ \\
\hline \multirow[t]{2}{*}{$\begin{array}{l}\text { Travel time to the nearest } \\
\text { station (minutes) }\end{array}$} & $-0.002^{* * *}$ & $-0.001^{* *}$ \\
\hline & $(0.001)$ & $(0.0005)$ \\
\hline Constant & $\begin{array}{l}12.574^{* * *} \\
(0.017)\end{array}$ & $\begin{array}{l}13.367^{* * *} \\
(0.015)\end{array}$ \\
\hline Observations & 1578 & 1361 \\
\hline $\mathrm{R}^{2}$ & 0.223 & 0.254 \\
\hline Adjusted $\mathrm{R}^{2}$ & 0.222 & 0.253 \\
\hline Residual Std. Error & $0.171(\mathrm{df}=1575)$ & $0.140(\mathrm{df}=1358)$ \\
\hline F Statistic & $225.663^{* * *}(\mathrm{df}=2 ; 1575)$ & $231.379^{* * *}(\mathrm{df}=2 ; 1358)$ \\
\hline
\end{tabular}

\section{Discussion}

Urban planners and decision makers seek to boost liveability in cities by-among other approaches-providing sustainable and affordable housing in an era of rising house prices around the world [20] and maintaining compact cities in spite of the phenomenon of urban sprawl [21]. Promoting sustainable mobility through the use of reliable and carefully planned public transport systems in response to congestion and emissions caused by private cars is one of the key measures to ensure accessibility in urban areas [22,23].

In this article, one of the key aspects of these challenges was analysed, namely the relationship between the price of a flat and its closeness to a metro or commuter railway station that provides fast connection to the city centre. To fill in a gap in the related extensive literature, a specific type of real estate was studied, namely panel flats in Budapest, featuring similar characteristics in terms of location, quality and design. Data on real estate from online advertisements and an administrative database were included in the study. The statistically significant results indicate that both hypotheses can be accepted, i.e., the quality of panel flats is unrelated to their closeness to metro and commuter railway stations or the CBD in terms of travel time (Hypothesis_1) and the price of panel flats is negatively correlated with this closeness (Hypothesis_2).

Previous evidence indicates that there is significant variation in the estimated effect of railway station accessibility on property prices. On the one hand, some studies suggest that direct nearness of residential buildings to railways or railway stations can have a negative impact on the price of flats due to negative externalities, such as noise and vibration. On the other hand, closeness in terms of accessibility is usually found to be positively linked with real estate value [14]. The magnitude of this effect may depend on the type of railway and the type of real estate. Here, a homogeneous type of real estate and the railway network of a specific city were considered. Numerical results showed that five additional minutes to/from the nearest metro or commuter railway station would add approximately 1 percent to the contract price in the case study. As the panel flats in dataset_2 are located 1 to 47 (on average: 18) minutes of travel time from the nearest metro or commuter railway station, in light of the above results, an average flat has an approximately 3.4 percent lower value than a flat located in the close vicinity $(1 \mathrm{~min})$ to the station. In spite of the different approaches and methods applied in the literature (see Table 1), this seems to be comparable to previous findings.

Besides the analysed variables, many other factors may influence (and have major effects on) real estate prices. Obviously, the quality of a flat is largely influential and other circumstances, such as the characteristics of the surrounding area, including available 
services, public safety and further mobility options, also play a relevant role in house sales [24]. As a potential future research topic, comparing residential property prices before and after major public transport development projects could significantly extend the results of this study. Opportunities to do so may arise from the ambitious strategy developed in Hungary in 2019-2020 (Budapest Suburban Railway Node Strategy), which defines comprehensive goals to increase the number of passengers by $80 \%$ on suburban railway lines by 2040, mainly by connecting suburban railway lines and increasing their capacity within city boundaries.

Taking into account the limitations of this research, particularly the limited data on sales (i.e., aggregate data of census tracts) and available information on housing estates, the above findings could be extended with the addition results obtained in similar contexts, e.g., in cities of other post-socialist countries, preferably on the basis of prices and characteristics of individual units. However, the application of a similar approach-even on the basis of a similar set of data-would allow the comparison among cities to reveal if the same relation with a similar magnitude exists between public transport connections and prices of highly uniform properties.

The policy implications of this research are twofold. First, the city in this case study may exploit outcomes in its ongoing and future public transport projects (as part of or independently from the above-mentioned strategy), particularly by land value capture instruments. Second, findings may be transferable to other contexts: (1) to real estate projects of flats with similar characteristics, where a similar magnitude of price differences may be attached to the distance from railway stations or the city centre and (2) even to diverse sets of houses, where this diversity has to be taken into account for the adaptation of the present outcomes.

In light of local, European and global initiatives to make urban areas more sustainable, most cities aim to extend and improve railway networks to provide fast, reliable and environmentally friendly commuting opportunities. Thus, understanding how these infrastructure investments impact residential property prices seems to be crucial. On the basis of the above and similar findings, the introduction of tailor-made value capture policies may help to co-fund investments and the careful design of land use and real estate projects can ensure that housing- and mobility-related objectives are mutually being met.

Author Contributions: Conceptualization, D.T. and A.M.; methodology, D.T. and A.M.; data curation, D.T.; formal analysis, D.T.; writing—original draft, D.T.; writing—review and editing, A.M.; visualization, D.T.; supervision, A.M. All authors have read and agreed to the published version of the manuscript.

Funding: This research received no external funding.

Institutional Review Board Statement: Not applicable.

Informed Consent Statement: Not applicable.

Data Availability Statement: Some or all data that support the findings of this study are available from the corresponding author upon reasonable request.

Conflicts of Interest: The authors declare no conflict of interest. 


\section{Appendix A}

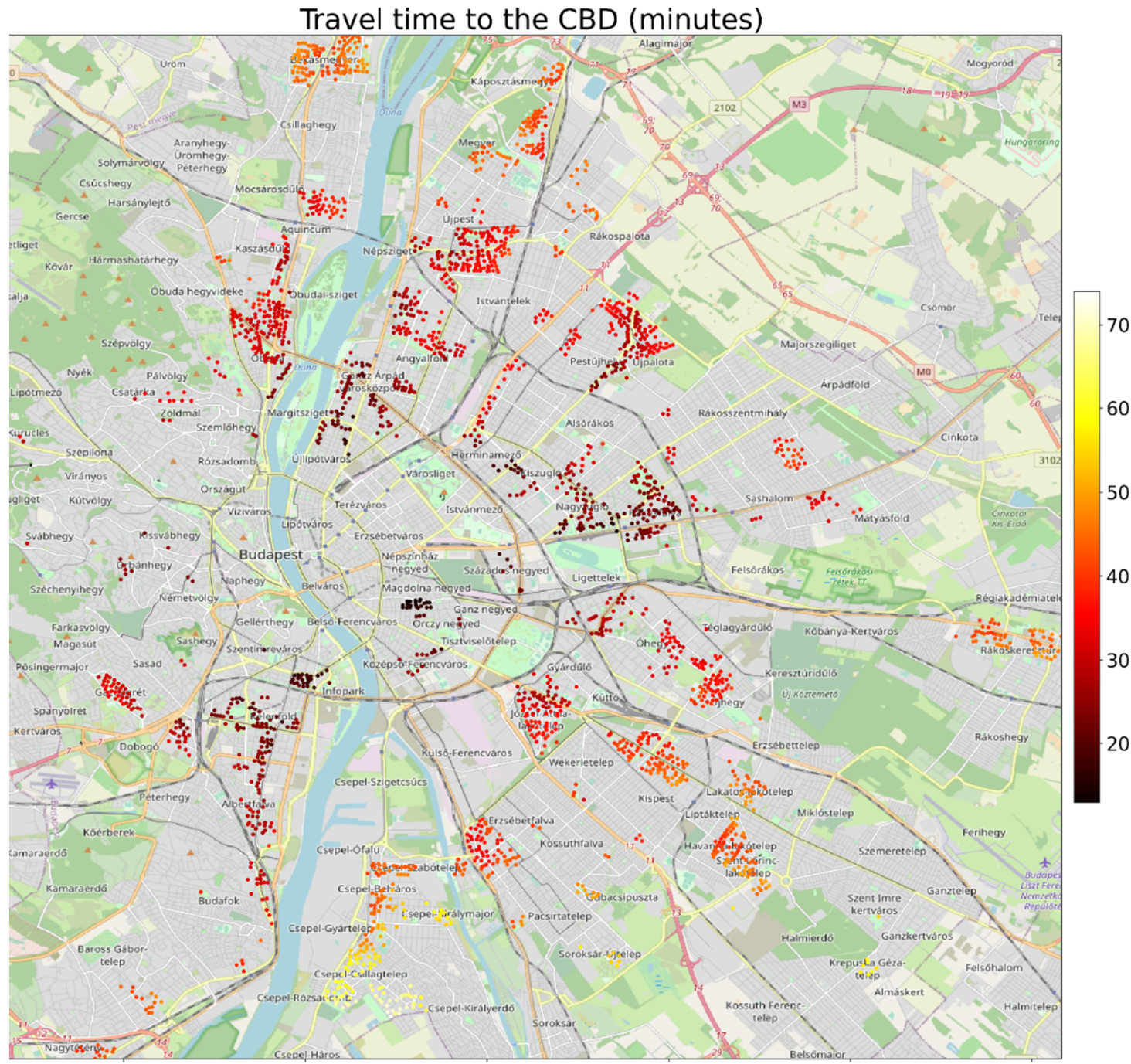

Figure A1. Travel time to the CBD from panel flats by public transport. Map data copyrighted OpenStreetMap contributors and available from https://www.openstreetmap.org, accessed on 20 December 2021.

\section{References}

1. UN Habitat World Cities Report 2020: The Value of Sustainable Urbanization. 2020. Available online: https: / unhabitat.org/ sites/default/files/2020/10/wcr_2020_report.pdf (accessed on 20 December 2021).

2. Ochoa, J.J.; Tan, Y.; Qian, Q.K.; Shen, L.; Moreno, E.L. Learning from Best Practices in Sustainable Urbanization. Habitat Int. 2018, 78, 83-95. [CrossRef]

3. UN Habitat New Urban Agenda. Available online: http://uploads.habitat3.org/hb3/NUA-English.pdf (accessed on 20 December 2021).

4. European Commission Sustainable and Smart Mobility Strategy. Putting European Transport on Track for the Future. Available online: https:/ / transport.ec.europa.eu/transport-themes/mobility-strategy_en (accessed on 20 December 2021).

5. Erdősi, S.; Gerőházi, É.; Teller, N.; Tosics, I. Large Housing Estates in Hungary: Overview of Developments and Problems in Budapest and Nyíregyháza; Faculty of Geosciences, Utrecht University: Utrecht, The Netherlands, 2003.

6. Alonso, W. Location and Land Use. Toward a General Theory of Land Rent; Harvard University Press: Cambridge, MA, USA, 1964.

7. Laakso, S. Public Transport Investment and Residential Property Values in Helsinki. Scand. Hous. Plan. Res. 1992, 9, 217-229. [CrossRef]

8. Grass, R.G. The Estimation of Residential Property Values around Transit Station Sites in Washington, D.C. J. Econ. Finan. 1992, 16, 139-146. [CrossRef] 
9. Dubé, J.; Thériault, M.; Des Rosiers, F. Commuter Rail Accessibility and House Values: The Case of the Montreal South Shore, Canada, 1992-2009. Transp. Res. Part A Policy Pract. 2013, 54, 49-66. [CrossRef]

10. Ibeas, Á.; Cordera, R.; dell'Olio, L.; Coppola, P.; Dominguez, A. Modelling Transport and Real-Estate Values Interactions in Urban Systems. J. Transp. Geogr. 2012, 24, 370-382. [CrossRef]

11. Cordera, R.; Coppola, P.; dell'Olio, L.; Ibeas, Á. The Impact of Accessibility by Public Transport on Real Estate Values: A Comparison between the Cities of Rome and Santander. Transp. Res. Part A Policy Pract. 2019, 125, 308-319. [CrossRef]

12. Debrezion, G.; Pels, E.; Rietveld, P. The Impact of Rail Transport on Real Estate Prices: An Empirical Analysis of the Dutch Housing Market. Urban Stud. 2011, 48, 997-1015. [CrossRef]

13. Andersson, D.E.; Shyr, O.F.; Fu, J. Does High-Speed Rail Accessibility Influence Residential Property Prices? Hedonic Estimates from Southern Taiwan. J. Transp. Geogr. 2010, 18, 166-174. [CrossRef]

14. Debrezion, G.; Pels, E.; Rietveld, P. The Impact of Railway Stations on Residential and Commercial Property Value: A MetaAnalysis. J. Real Estate Finan. Econ. 2007, 35, 161-180. [CrossRef]

15. Mohammad, S.I.; Graham, D.J.; Melo, P.C.; Anderson, R.J. A Meta-Analysis of the Impact of Rail Projects on Land and Property Values. Transp. Res. Part A Policy Pract. 2013, 50, 158-170. [CrossRef]

16. Higgins, C.D.; Kanaroglou, P.S. Forty Years of Modelling Rapid Transit's Land Value Uplift in North America: Moving beyond the Tip of the Iceberg. Transp. Rev. 2016, 36, 610-634. [CrossRef]

17. Benkő, M. Evaluating Factors in the Image of Housing Estates. Period. Polytech. Archit. 2012, 43, 33-36. [CrossRef]

18. eNET Ha Apróhirdetés, Akkor Jófogás, Ha Ingatlanhirdetés, Akkor Ingatlan.Com Szegmentáció Az Online Apróhirdetési Piacon, Fókuszban Az Ingatlanhirdetések. 2018. Available online: https://www.enet.hu/wp-content/uploads/2018/09/eNET-BCE_ online_aprohirdetesi_piac_teljes_tanulmany.pdf (accessed on 20 December 2021).

19. Remenyik, B.; Barcza, A.; Csapó, J.; Szabó, B.; Fodor, G.; Dávid, L.D. Overtourism in Budapest: Analysis of Spatial Process and Suggested Solutions. Reg. Stat. 2021, 11, 179-197.

20. Moghayedi, A.; Awuzie, B.; Omotayo, T.; Le Jeune, K.; Massyn, M.; Ekpo, C.O.; Braune, M.; Byron, P. A Critical Success Factor Framework for Implementing Sustainable Innovative and Affordable Housing: A Systematic Review and Bibliometric Analysis. Buildings 2021, 11, 317. [CrossRef]

21. Alonso, A.; Monzón, A.; Wang, Y. Modelling Land Use and Transport Policies to Measure Their Contribution to Urban Challenges: The Case of Madrid. Sustainability 2017, 9, 378. [CrossRef]

22. Földes, D.; Csiszár, C. Route Plan Evaluation Method for Personalised Passenger Information Service. Transport 2015, 30, 273-285. [CrossRef]

23. Hörcher, D.; Tirachini, A. A Review of Public Transport Economics. Econ. Transp. 2021, 25, 100196. [CrossRef]

24. Bowes, D.R.; Ihlanfeldt, K.R. Identifying the Impacts of Rail Transit Stations on Residential Property Values. J. Urban Econ. 2001, 50, 1-25. [CrossRef] 